\title{
Anthropometric and Physical Fitness Characteristics of Elite Futsal Tunisian Players
}

\author{
Trabelsi $\mathbf{Y}^{1,2}$, Aouichaoui $\mathrm{C}^{1,2,3, *}$, Richalet $\mathrm{JP}^{4}$, Tabka $\mathrm{Z}^{1}$ \\ ${ }^{1}$ Université de Sousse, Laboratoire de Physiologie et des Explorations Fonctionnelles, Faculté de Médecine de Sousse, Sousse, Tunisie \\ ${ }^{2}$ Université de Sfax, Institut Supérieur du Sport et de l’Education Physique de Sfax, Sfax, Tunisie \\ ${ }^{3}$ Université de Gafsa, Institut Supérieur du Sport et de l’Education Physique de Gafsa, Gafsa, Tunisie \\ ${ }^{4}$ Université Paris 13, Laboratoire "Réponses Cellulaires et Fonctionnelles à l’hypoxie" EA 2363, Bobigny, France \\ *Corresponding author: chirineaouichaoui@yahoo.com
}

Received April 22, 2014; Revised May 15, 2014; Accepted May 28, 2014

\begin{abstract}
The purposes of this study are to establish the relationships among vertical jumping parameters, aerobic fitness and sprint running performance and to examine the anthropometric and physiological profile in elite Futsal Tunisian players. Twenty-six elite Tunisian Futsal players (age $26 \pm 3$ years, height $1.77 \pm 0.75 \mathrm{~m}$, weight $69.3 \pm 8.5$ $\mathrm{Kg}$ ) volunteered to participate in this study. On separate days, all participants were asked to perform physical performance tests (Squat jump (SJ), countermovement jump (CMJ), sprint and aerobic power test (20-m shuttle run). Pearson's correlation coefficient and multiple regression analysis were used to analyze the data set and to identify which variables significantly influence sprint performance variables. We have found in the current study a negative association between $10 \mathrm{~m}$ sprint time and maximal oxygen uptake $(\mathrm{r}=-0.44, \mathrm{p}<0.05)$. Leg anaerobic power characteristics were inversely related to $20 \mathrm{~m}(\mathrm{r}=-0.46)$ and $10 \times 5 \mathrm{~m}$ sprint time $(\mathrm{r}=-0.41)$. Therefore, muscle power and maximum oxygen uptake seem to be important physiological characteristics for sprinting performance in elite Futsal Tunisian players. This study could help practitioners and coaches to better design training by emphasizing the importance of combining adapted leg muscular power training with sprint running training programs for improving short-distance sprint performance.
\end{abstract}

Keywords: indoor soccer, sprint performance, vertical jumps, maximal oxygen uptake

Cite This Article: Trabelsi Y, Aouichaoui C, Richalet JP, and Tabka Z, "Anthropometric and Physical Fitness Characteristics of Elite Futsal Tunisian Players." American Journal of Sports Science and Medicine, vol. 2, no. 4 (2014): 136-142. doi: 10.12691/ajssm-2-4-4.

\section{Introduction}

Futsal is the official five-a-side indoor soccer game and the only indoor soccer recognized by soccer's international governing body (Federation Internationale de Football Association, FIFA). Il is an intermittent highintensity strenuous team sport played worldwide that places heavy emphasis on running speed and endurance and requires substantial strength levels to kick, tackle, turn, change pace and sprint during actions. The game is growing in popularity all over the world (12 million players in more than 100 countries) and since 1989 the world championships have been contested by 16 national teams every 4 years [13].

Futsal is a small-sided game (5v5 including the goalkeepers) that requires high physical, technical, and tactical capacity from the players. It is played on a 38-42 $\mathrm{m} \times 20$-25 m pitch during two 20-min clock time halves, with the clock stopped for some events that can result in a total duration game of 70-80 min. Teams can request one time out $(1 \mathrm{~min})$ in each half and there is a break of 10 min between halves and an unlimited number of substitutions are permitted [3]. However, it has its own character using aspects of different sports (basketball, handball, and football). Barbero-Alvarez et al. [3] revealed that Futsal is a multiple sprint sport presenting more highintensity phases than soccer and other intermittent sports.

The mean heart rate and the percentage of maximum heart rate recorded during Futsal play were generally higher than those recorded in football, handball, and basketball matches [3]. It has been proven that Futsal players develop quicker reflexes, faster thinking and pinpoint passing [3]. Consequently the physical demands might be very high [3]. Doğramaci and Watsford [11] estimated that during competitive matches, Futsal players cover at high intensity $26 \%$ of total game distance or time. Moreover, indoor football requires a cardiovascular demand of 85 to $90 \%$ of maximal heart rate, in most matches reaching maximum heart rate [1]. Recently, Castagna and Barbero-Álvarez [9] showed that Futsal played at professional level is a high intensity exercise, heavily taxing the aerobic and anaerobic pathways.

Futsal requires physical and physiological demands on its participants, which become more pronounced with high level of competition. The physical demands are related both to technical aspects of the game and its physical contact elements. The physiological demands are linked to the intensity at which the game is played. Success in a 
team sport such as Futsal depends on how individual characteristics are blended within the team to form a coherent playing system. This makes the interpretation of physiological profiles of individual players more difficult than in individual sports such as athletics, cycling and swimming where the relationship between physiological capacities and sport performance can be outlined more precisely [9]. Nevertheless, the determination of the physical and physiological profiles of the Tunisian elite Futsal players can provide useful information for both the team as a whole and for the individuals who comprise it. It can also help in identifying strengths and weaknesses in individual players within the team compared to the profile of professional Futsal players. Anthropometric profile is an important selective factor for success in sport [28].

Only a few studies have analyzed some anthropometric $[3,10,13]$ and aerobic power $[3,4,10,13]$ characteristics of elite Futsal players among European and South American countries.

Despite its popularity and its competitive status, it is somewhat surprising to find only little information concerning the muscle power, aerobic capacity and association between muscle power and sprint running performance of current world class elite Futsal players. Knowledge of the anthropometric and physiological characteristics of elite Futsal players is of great importance since it should allow Futsal coaches to control strength/power and endurance training programs in order to adapt their players to the physiological requirements of their sport [9].

An important question is how are the sprint variables related to vertical jumping ability and aerobic fitness in elite Futsal Tunisian players? We hypothesized that vertical jumping parameters and aerobic fitness influence sprinting performance among elite Futsal Tunisian players. Therefore, the first aim of the present study is to determine the possible relationships between aerobic power (maximal oxygen uptake), anaerobic power (vertical jumping test) and sprint running performance. The second aim is to examine the anthropometric and physiological profile of elite Futsal Tunisian players.

\section{Methods}

\subsection{Experimental Approach to the Problem}

To quantify the relationship between vertical jumping performance, aerobic fitness and sprint performance and to examine the anthropometric and physiological profile of elite Futsal Tunisian players, 26 Futsal players were asked to perform $20 \mathrm{~m}$ shuttle run, sprint, Squat jumps (SJ) and Countermovement jump (CMJ) tests. Pearson's correlation coefficient and multiple regression analysis were used to analyze the data set to determine the possible relationships among aerobic fitness, anaerobic power and sprint running performance. The dependent variables were sprint performance parameters. The independent variables were jump performance measures and maximal oxygen uptake $\left(\mathrm{VO}_{2 \max }\right)$.

\subsection{Subjects}

Twenty-six elite Futsal players from Tunisian National team took part in this study. Their mean age, height and weight were $26.1 \pm 3$ (21-36) years, $177 \pm 0.07$ (164-197) $\mathrm{cm}$ and $69.3 \pm 8.5$ (56.9-87.0) kg, respectively. The players, with an active playing career of about 6 years, trained five times per week for 90 minutes per training session and participated in Tunisian Futsal Championship once a week.

Before starting the study, players had a physical examination and they answered to a medical questionnaire. Tests were performed in 31 Futsal players, some players did not perform adequately the vertical jumping $(n=2)$ and the sprint $(n=3)$ tests. Finally, 26 Futsal players were included in the subsequent analysis.

Prior to the study, the coach and the subjects had been fully informed of the aim of the experimental procedure of the investigation before signing a written consent, which was in accordance with legal requirements and the Declaration of Helsinki, and was approved by the Tunisian Ministry of Youth and Sports and by the Research Ethics Committee of Farhat Hached Hospital (Sousse).

\subsection{Test Procedures}

All subjects completed two preliminary familiarization sessions to minimize any effects of learning and to be informed about pretest instructions.

All the tests were performed during March 2010 in the afternoon, in the same order and in the same facilities. Testing was conducted over 4 separate sessions, separated by at least 2 days. During the first testing session, each subject was subjected to anthropometrical measurements. In the second test session, each subject was subjected to vertical jumping test. In the third testing session, sprint tests were measured and finally in the fourth session each subject was subjected to graded 20 -m shuttle run test.

Players were told to refrain from heavy training, alcohol, caffeine, and tobacco usage for the 2 days preceding testing sessions. Only drinking water was allowed 2 hours before the test. As for heavy meals, the players were asked to stop taking in any foods before 3 hours of the testing sessions. The subjects were not taking any medications that would have an impact on the results of the current study. A comfortable average air temperature of about $20^{\circ} \mathrm{C}$ existed in all tests. Before each test, subjects performed a standard 15- to 20-minute warm-up. The test-retest intraclass correlation coefficients of the testing procedure variables used in this study were $>0.91$ and the coefficients of variation ranged from 0.9 to $7.3 \%$.

\subsection{Physical characteristics}

The anthropometric measurements included height, weight and circumferences such, waist, upper-thigh, lower-thigh and calf girth. Subjects were weighed in minimal clothing using a digital scale (Harpenden Balance Scale, UK) to the nearest $0.1 \mathrm{~kg}$. Standing and sitting heights were measured with an appropriate stadiometer (Harpenden Portable Stadiometer, UK) to the nearest 0.1 $\mathrm{cm}$ and the circumferences were measured to the nearest $0.1 \mathrm{~cm}$ using a non-elastic measuring tape. The difference between the standing height and the sitting height allowed us to determine the leg length. Body mass index (BMI) was calculated as weight $(\mathrm{kg})$ divided by the square of the height (m). 
Lower body impedance was measured with a Tanita TBF-604 Body Fat Monitor/Scale (Tokyo, Japan). This device requires the input of data describing the body mass, standing height, and sex of the subject who then stands on the scale, which contains the source and detector electrodes in the areas that contact the plantar surfaces of both feet. It measures lower body impedance and then calculates the body fatness (fat percentage).

Absolute body fat weight was calculated as follows: fat weight $(\mathrm{kg})=\%$ fat $\times$ (weight $/ 100)$. For determining fatfree weight $(\mathrm{kg})$, it has been calculated by subtracting fat weight from total body weight [8].

\subsection{Performance Tests}

\subsubsection{Vertical Jumping Test}

Jumping performance was evaluated with the Optojump device (Microgate SRL, Italy) connected to a portable computer where data were recorded (Jump height, power, flight and contact times).

On an indoor court, vertical jumps were measured with both squat jump (SJ) and countermovement jump (CMJ) protocols. The Futsal players were given two practice jumps before the specific jump test was conducted. The best of three attempts to the nearest within a centimeter was recorded. The jumps were separated by a two- minute rest period to ensure sufficient recovery.

For all jumps, Futsal players retained their hands on their hips to eliminate the influence of the arms swing impulse. For the SJ test, they were instructed to go down and hold a knee position (approximately $120^{\circ}$ Knee angle) for three seconds. On the count of three, the player was instructed to jump as high as possible without performing any countermovement before the execution of the jump. A successful trial was one where there was no sinking or countermovement prior to the execution of the jump [15].

The CMJ assessment required the player to be in a standing position and, prior to jumping, counter-moved until the knee was flexed approximately to $90^{\circ}$. They were then instructed to go down as quickly as possible and then jump as high as possible in the ensuing concentric phase. Verbal encouragements were constantly given to maintain high motivation in these groups [15]. All subjects performed 3 consecutive experimental trials for each jump. The best values for each jump were retained for further analysis. Players performed jumps in comfortable clothing and running shoes.

\subsubsection{Sprint Tests}

The sprint tests were preceded by standardized warmups which started with a low-intensity run followed by stretching exercises supervised by coaches. Dynamic exercises aimed at improving suppleness of muscle groups, essential in sprints: flexors and extensors of the hip, knee and ankle joints [22].

The times for $10 \mathrm{~m}, 20 \mathrm{~m}$ and $10 \times 5 \mathrm{~m}$ sprint tests of players were measured using photocell gates (Brower Timing Systems, Salt Lake City, UT, USA; accuracy of 0.01 seconds). When ready to sprint, the subjects commenced the sprint from a standing start, $0.5 \mathrm{~m}$ behind the start. Stance for the start was consistent for each subject. The time was automatically activated as the subject passed the first gate at the $0 \mathrm{~m}$ mark and split times were recorded at $10 \mathrm{~m}, 20 \mathrm{~m}$ and $10 \times 5 \mathrm{~m}$. Each participant had 3 trials separated by at least 5 minutes of rest, and the fastest time, measured to the nearest $0.01 \mathrm{~s}$, was used as the speed score.

Athletes performed sprints in tight fitting clothing and track spike shoes. Participants were given verbal encouragement to perform maximally during sprints.

\subsubsection{Aerobic Power Test-Twenty-Meter Shuttle Run Test}

The maximal multistage 20-m shuttle run test, described by Léger and Lambert [19] and modified by Léger et al. [20], was used to evaluate maximal aerobic capacity from maximal aerobic speed. Participants were required to run between two lines $20 \mathrm{~m}$ apart. The pace was dictated by a cassette tape emitting tones at prescribed intervals. The initial speed was set at $8.5 \mathrm{~km}$. $\mathrm{h}^{-1}$ for the first minute and was increased $0.5 \mathrm{~km} . \mathrm{h}^{-1}$ for each subsequent minute.

When runners could no longer keep up the pace by reaching the line at the time of the tone, participation was terminated and the number of laps completed was recorded [19]. Scores of the last stage number were converted to predict maximal oxygen uptake $\left(\mathrm{VO}_{2} \max \right)$ [20]. $\mathrm{VO}_{2}$ max was expressed in $\mathrm{ml}$ of oxygen consumed per kilogram of body weight and per minute $\left(\mathrm{ml} . \mathrm{kg}^{-1}\right.$. $\min ^{-1}$ ).

Maximal Aerobic Speed (MAS) is the lowest speed enabling you to obtain the $\mathrm{VO}_{2}$ max which the level of maximum aerobic power for a subject. During the test, the participants were verbally, encouraged to run as long as possible.

\subsection{Statistical Analyses}

Results are expressed as the mean \pm standard deviation (SD). Data were screened for normality using the Kolmogorv-Smirnov test and summarized using descriptive statistics. Pearson's correlation coefficient and multiple regression analysis (forward stepwise) were conducted to determine the relationships between vertical jumping performance, sprint performance, maximal aerobic power and anthropometric parameters. The level of significance was set a $\mathrm{p}<0.05$. The Statistical Package for Social Sciences (SPSS) (version 17.0) software package and STATISTICA 6.0 package were used to analyze all data.

\section{Results}

\subsection{Physical Characteristics and Body Composition of Elite Futsal Tunisian Players}

Twenty-six Futsal Tunisian players were included in the present study. Mean \pm standard deviation, minimum and maximum of physical characteristics and body composition in elite Futsal Tunisian players are presented in Table 1.

\subsection{Jumping and Sprinting Performance}

Mean \pm standard deviation, minimum and maximum for sprint performance and jump performance variables of elite Futsal Tunisian players are presented in Table 2. 
Jump height and average power of Futsal players during $\quad$ higher $(\mathrm{p}<0.05)$ than during squat Jump test (SJ) (Table 2). the Countermovement Jump (CMJ) test were significantly

Table 1. Mean \pm standard deviation, minimum and maximum of physical characteristics and body composition in elite Futsal Tunisian players

\begin{tabular}{cccc}
\hline & & & \\
\hline & Futsal players $(\mathrm{n}=26)$ & Minimum & Maximum \\
\hline Age (y) & Mean \pm SD & 21 & 36 \\
Standing height (m) & $26 \pm 3$ & 1.64 & 1.97 \\
Sitting height (m) & $1.77 \pm 0.07$ & 0.87 & 0.99 \\
Weight (kg) & $0.92 \pm 0.03$ & 56.9 & 87.0 \\
Body mass index (kg.m- ${ }^{2}$ ) & $69.3 \pm 8.5$ & 19.3 & 25.5 \\
Leg length (m) & $21.8 \pm 1.6$ & 0.77 & 0.98 \\
Waist size (m) & $0.85 \pm 0.05$ & 0.73 & 0.89 \\
Upper thigh girth (m) & $0.78 \pm 0.04$ & 0.49 & 0.62 \\
Lower thigh girth (m) & $0.54 \pm 0.03$ & 0.41 & 0.49 \\
Calf girth (m) & $0.44 \pm 0.02$ & 0.31 & 0.38 \\
Percent body fat (\%) & $0.34 \pm 0.02$ & 7.0 & 16.9 \\
Absolute body fat (kg) & $12.20 \pm 3.41$ & 3.98 & 12.62 \\
Fat-free weight (kg) & $8.65 \pm 3.08$ & 51.75 & 74.39 \\
\hline
\end{tabular}

Table 2. Mean \pm standard deviation, minimum and maximum of aerobic fitness, sprint and jump performance measures in elite Futsal Tunisian players

\begin{tabular}{|c|c|c|c|}
\hline \multicolumn{4}{|c|}{ Futsal players $(n=26)$} \\
\hline & Mean \pm SD & Minimum & Maximum \\
\hline \multicolumn{4}{|l|}{ Sprint performance measures } \\
\hline 10 m sprint time (s) & $1.79 \pm 0.08$ & 1.54 & 1.90 \\
\hline 20m sprint time (s) & $3.19 \pm 0.15$ & 2.83 & 3.50 \\
\hline $10 \times 5 \mathrm{~m}$ sprint time (s) & $14.52 \pm 0.27$ & 14.11 & 14.99 \\
\hline \multicolumn{4}{|l|}{ Maximal aerobic power } \\
\hline $\mathrm{VO}_{2 \max }\left(\mathrm{ml} \cdot \mathrm{min}^{-1} \cdot \mathrm{kg}^{-1}\right)$ & $54.21 \pm 3.41$ & 48.30 & 61.90 \\
\hline $\operatorname{MAV}\left(\mathrm{km} \cdot \mathrm{h}^{-1}\right)$ & $13.62 \pm 0.56$ & 12.60 & 14.90 \\
\hline \multicolumn{4}{|l|}{ Squat Jump measures } \\
\hline Height (m) & $0.30 \pm 0.04$ & 0.22 & 0.40 \\
\hline Average power $\left(\mathrm{w} \cdot \mathrm{kg}^{-1}\right)$ & $19.12 \pm 3.21$ & 15.31 & 25.59 \\
\hline Contact time (s) & $1.04 \pm 0.32$ & 0.52 & 1.68 \\
\hline Flight time (s) & $0.48 \pm 0.10$ & 0.24 & 0.83 \\
\hline \multicolumn{4}{|c|}{ Countermovement jump measures } \\
\hline Height $(\mathrm{m})$ & $0.33^{*} \pm 0.03$ & 0.26 & 0.38 \\
\hline Average power $\left(\mathrm{w} \cdot \mathrm{kg}^{-1}\right)$ & $22.82 * \pm 5.47$ & 16.03 & 33.85 \\
\hline Contact time (s) & $1.06 \pm 0.35$ & 0.41 & 1.71 \\
\hline Flight time (s) & $0.50 \pm 0.04$ & 0.40 & 0.58 \\
\hline
\end{tabular}

* Significant difference between jump height and average power during Countermovement jump and Squat jump ( $<0.05)$

$\mathbf{V O}_{2 \max }$ Maximum oxygen uptake

MAV Maximum Aerobic Velocity

Table 3. Pearson correlation coefficients between vertical jumping parameretrs, aerobic fitness and sprint performance measures in elite Futsal Tunisian players

\begin{tabular}{|c|c|c|c|c|c|c|c|c|c|c|c|c|c|}
\hline & 1 & 2 & 3 & 4 & 5 & 6 & 7 & 8 & 9 & 10 & 11 & 12 & 13 \\
\hline (1) CMJ power (W.Kg-1) & 1,00 & & & & & & & & & & & & \\
\hline (2) CMJ height (m) & 0.11 & 1,00 & & & & & & & & & & & \\
\hline (3) CMJ contact time (s) & $-0.38 *$ & -0.17 & 1.00 & & & & & & & & & & \\
\hline (4) CMJ flight time (s) & 0.05 & 0.37 & 0.08 & 1.00 & & & & & & & & & \\
\hline (5) SJ power (W.Kg-1) & 0.16 & 0.00 & -0.31 & 0.20 & 1.00 & & & & & & & & \\
\hline (6) SJ height (m) & 0.23 & 0.10 & -0.16 & $0.42 *$ & $0.39 *$ & 1.00 & & & & & & & \\
\hline (7) SJ contact time (s) & -0.32 & -0.35 & $0.48^{*}$ & -0.12 & 0.00 & 0.04 & 1.00 & & & & & & \\
\hline (8) SJ flight time (s) & 0.15 & -0.09 & -0.17 & 0.20 & $0.58 * *$ & $0.59 * *$ & 0.07 & 1.00 & & & & & \\
\hline (9) $\mathrm{VO} 2_{\max }(\mathrm{ml}$. min-1.kg-1) & 0.00 & -0.00 & 0.04 & 0.25 & 0.34 & 0.13 & -0.19 & 0.04 & 1.00 & & & & \\
\hline (10) MAV (km.h-1) & 0.03 & 0.01 & 0.02 & 0.25 & 0.35 & 0.14 & -0.21 & 0.05 & $0.99 * *$ & 1.00 & & & \\
\hline (11) $10 \mathrm{~m}$ Sprint time (s) & -0.31 & 0.30 & -0.02 & 0,02 & -0.06 & -0.07 & 0.08 & -0.00 & $-0.44^{*}$ & $-0.44 *$ & 1.00 & & \\
\hline (12) $20 \mathrm{~m}$ sprint time (s) & -0.16 & 0.22 & -0.24 & $-0,46^{*}$ & -0.21 & $-0.46^{*}$ & -0.38 & -0.21 & -0.29 & -0.29 & 0.31 & 1.00 & \\
\hline (13) $10 * 5 \mathrm{~m}$ Sprint time (s) & -0.18 & -0.06 & 0.04 & $-0,20$ & $-0.41 *$ & -0.12 & 0.09 & -0.06 & -0.06 & -0.09 & -0.03 & 0.18 & 1.00 \\
\hline
\end{tabular}

$* \mathrm{p}<0.05 * * \mathrm{p}<0.01$

$\mathbf{V O}_{\text {max }}=$ Maximum oxygen uptake

MAV = Maximum Aerobic velocity

CMJ = Counter-Movement Jump

$\mathbf{S J}=$ Squat Jump 


\subsection{Relationships between Vertical Jumping Parameters and Sprint Performance in Tunisian Futsal Players}

\subsubsection{Correlations}

The Pearson correlations coefficients of all jump performance variables with sprint performance measures were summarized in Table 3.

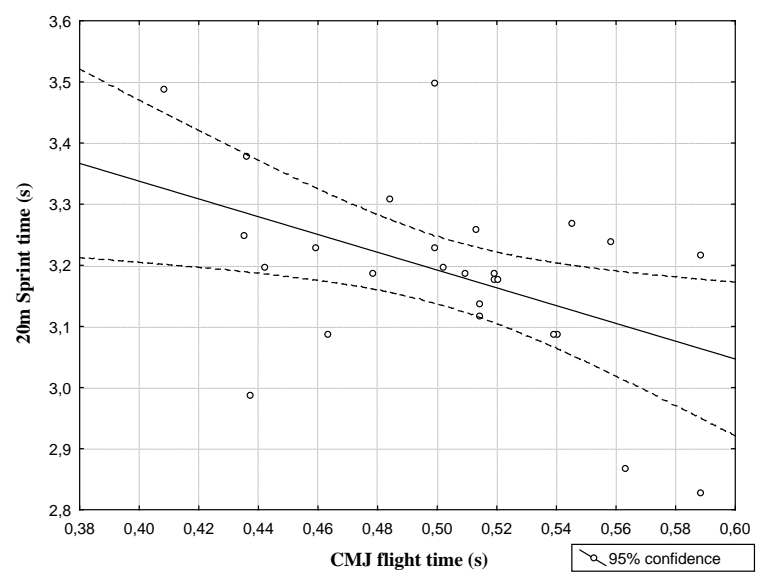

Figure 1. The relationship between $20 \mathrm{~m}$ sprint time and CMJ flight time in Tunisian Futsal players $(r=-0.46, p<0.05)$. Dotted lines represent $95 \%$ estimation interval

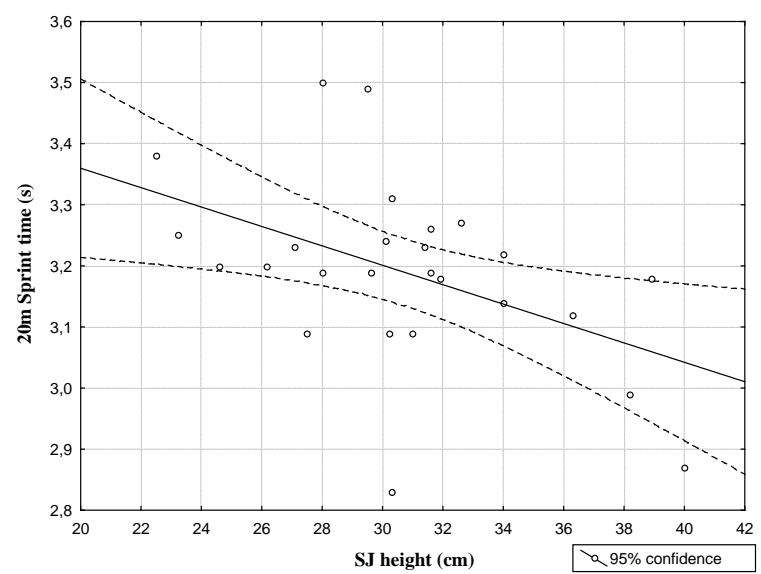

Figure 2. The relationship between $20 \mathrm{~m}$ sprint time and SJ height in Tunisian Futsal players ( $r=-0.46, \mathrm{p}<0.05$ ). Dotted lines represent $95 \%$ estimation interval

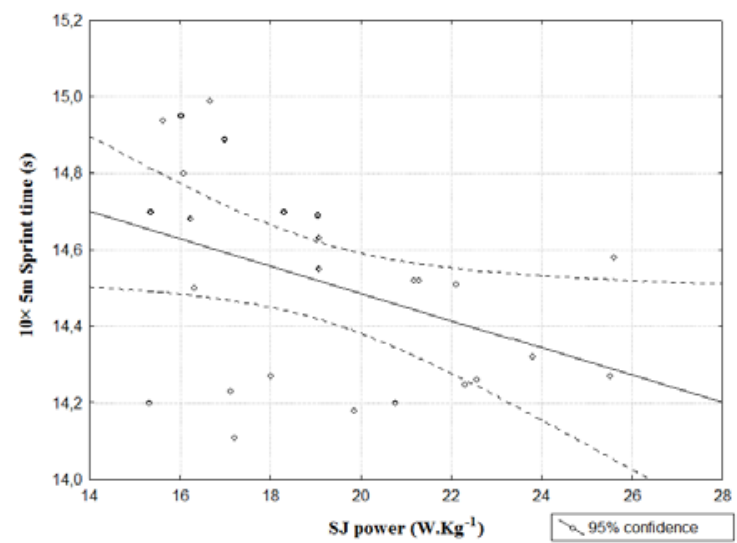

Figure 3. The relationship between $10 \times 5 \mathrm{~m}$ sprint time and SJ power in Tunisian Futsal players $(r=-0.41, \mathrm{p}<0.05)$. Dotted lines represent 95\% estimation interval
Correlation coefficients were calculated to check the influence of interaction. $20 \mathrm{~m}$ sprint time was correlated significantly with both CMJ flight time and SJ height $(\mathrm{r}=$ 0.46, $\mathrm{p}<0.05$ ) (Figures 1 and 2). $10 \times 5 \mathrm{~m}$ sprint time was correlated inversely with SJ power $(r=-0.41, \mathrm{p}<0.05)$ (Figure 3).

\subsection{Predictors of Sprint Performance}

A stepwise multiple regression analysis was used to determine the best predictors of $10 \mathrm{~m}, 20 \mathrm{~m}$ and $10 \times 5 \mathrm{~m}$ sprint performance. Our result showed a negative association between $10 \mathrm{~m}$ sprint performance and $\mathrm{VO}_{2}$ max in elite Tunisian Futsal players $(r=-0.44, p<0.05)$. SJ height and SJ contact time were significant predictors of $20 \mathrm{~m}$ sprint performance.

The following equation explained $35 \%$ of the $20 \mathrm{~m}$ sprint performance variability:

$20 \mathrm{~m}$ sprint time $=3.836-(0.366 \times$ SJ contact time $)-$ (0.450× SJ height).

Likewise, SJ power was the strongest predictor of $10 \times 5$ m sprint performance:

$10 \times 5 \mathrm{~m}$ sprint time $=15.198-(0.413 \times \mathrm{SJ}$ power $)$

3.2.1. Relationships between Aerobic Performance, Vertical Jumping Variables and Anthropometric Parameters in Tunisian Futsal Players

The analysis of stepwise multiple regression showed that the percentage of fat was negatively associated with $\mathrm{VO}_{2}$ max $(\mathrm{r}=-0.41, \mathrm{p}<0.05)$. The weight appeared to be a determinant of CMJ height jump $(r=-0.41, \mathrm{p}<0.05)$.

The anthropometric dimensions measured in this study revealed poor, insignificant relationships with sprinting performance (data not shown).

\section{Discussion}

The aims of the present study were to determine the relationships between vertical jumping parameters, aerobic fitness and sprint running performance and to examine the anthropometric and physiological profile of elite Futsal Tunisian players.

The measurements of performance in vertical jump are objectively provided by the Optojump system, which is valid for jump height estimation [12]. The CMJ and SJ were chosen because they have been found to be the most reliable and valid field tests for assessing the explosive power output of the lower limbs in active subjects [23]. We only selected Futsal players whose jumping performance was found to be reproducible. The times for $10 \mathrm{~m}, 20 \mathrm{~m}$ and $10 \times 5 \mathrm{~m}$ sprint tests of players were provided by photocell gates device which was very often the only device for the reliable measuring sprint performance [7,27]. Aerobic fitness was considered as evaluated by maximal oxygen uptake $\left(\mathrm{VO}_{2}\right.$ max $)$, which is a widely used parameter in sports medicine, especially for planning and monitoring training season [3]. The maximal multistage 20-m shuttle run test was designed by Léger and Lambert in order to assess a Futsal player's aerobic capacity. This test incorporates a number of activity patterns thought to reflect the intermittent activity profile of a Futsal match. It has previously been found to be a valid and reliable method of estimating the velocity associated with $\mathrm{VO}_{2 \max }[5,16,18]$. 


\subsection{Physical Characteristics}

To the best of our knowledge, only few studies simultaneously analyzed anthropometric, muscle power output and sprint performance in elite Futsal players $[2,3,10]$. Age and height observed in the present study showed similar average values compared to those reported in Spanish male elite indoor soccer players [13], whereas there were some differences between groups in body weight, body mass index, percent body fat and fat free mass. On the contrary, it is difficult to compare results of physical fitness, sprinting and vertical jumping data among elite Futsal players with other studies due to age group differences, variability in procedures and methodologies. In order to better describe the physiological profile of Futsal Tunisian players, we presented some variables not measured in other Futsal studies such as sitting height, leg length, waist size, upper thigh girth, lower thigh girth and calf girth.

\subsubsection{Relationships between Aerobic Power and Sprint Performance}

Sprint performance, measured as the mean sprint time in seconds, is an indicator of Futsal performance. We have found in the current study a negative association between $10 \mathrm{~m}$ sprint time and maximal oxygen uptake $\left(\mathrm{VO}_{2 \max }\right)$ $(\mathrm{r}=-0.44, \mathrm{p}<0.05)$. In this regard, Impellizzeri et al. [14] showed that small-sided games (i.e., 5-a-side drills) promote $\mathrm{VO}_{2 \text { max }}$ improvements similar to what is observed in interval running. As a consequence, Futsal training may be a plausible argument to explain the association between $\mathrm{VO}_{2 \text { max }}$ and $10 \mathrm{~m}$ sprint performance. Similarly, Wisløff et al. [30] considered that the increase in distance covered, the intensity of play and the number of sprints performed and ball involvements were associated with an elevated $\mathrm{VO}_{2 \max }$ in soccer players.

The mean $\mathrm{VO}_{2}$ max of $54.2 \mathrm{ml}$. $\mathrm{min}^{-1}$. $\mathrm{kg}^{-1}$ observed in the elite Tunisian Futsal players can be compared to values reported in similar studies. Barbero Alvarez et al. [2] found in Italian semi-professional and in Spanish professional Futsal players a mean $\mathrm{VO}_{2}$ max of $55.2 \mathrm{ml}$. $\mathrm{min}^{-1} \cdot \mathrm{kg}^{-1}$ and $62.8 \mathrm{ml} . \mathrm{min}^{-1} . \mathrm{kg}^{-1}$, respectively. Lima et al. [21] evaluated 13 professional Futsal players with a mean age of 18.6 years, and observed a $\mathrm{VO}_{2}$ max of $62.8 \mathrm{ml}$. $\mathrm{min}^{-1} . \mathrm{kg}^{-1}$ (direct measurement through ergospirometry) and $58.5 \mathrm{ml}$. $\mathrm{min}^{-1} . \mathrm{kg}^{-1}$ (indirect measurement through a $3200 \mathrm{~m}$ field test). Leal Junior et al. [17] observed in 12 professional players with a mean age of 20.9 years, a mean $\mathrm{VO}_{2}$ max of $55.7 \mathrm{ml}$. $\mathrm{min}^{-1}$. $\mathrm{kg}^{-1}$. Additionally, Castagna et al. [10] evaluated 8 professional Futsal players with a mean age of 22.4 years and found a $\mathrm{VO}_{2}$ max of $64.8 \mathrm{ml} . \mathrm{min}^{-1} . \mathrm{kg}^{-1}$. This discrepancy in results could be due to differences in the methods of analysis, as well as the different standards of participants taking part in the studies (professional, semi- professional, elite,..). A recent study showed that $\mathrm{VO}_{2}$ max was considered as a discriminative physiological variable in Futsal players of different levels [2]. This is in line with what was previously reported by several authors for soccer players [29]. Differences may be the result of genetic factors, player selection and training participation [2].

4.1.2. Relationships between Leg Power and Sprint Performance
In order to determine the profile of Tunisian Futsal player, we also analyzed the relationships between vertical jumping and sprint performance which is an indicator of Futsal performance. In the current study, power qualities were inversely related to $20 \mathrm{~m}(\mathrm{r}=-0.46)$ and $10 \times 5 \mathrm{~m}$ sprint time $(r=-0.41)$. The negative correlations between leg anaerobic power characteristics and sprint performance in the Tunisian Futsal players suggest that those with higher vertical jump performance tend to have lower sprint times which are in line with the study by Bosco et al. [6] concerning the elite male soccer players. The result of the present study is in accordance with the study of Maulder et al. [24] who revealed that CMJ and SJ were predictive of $10 \mathrm{~m}$ sprint performance. Not only was the power generated during a CMJ important to sprint performance but the power generated during SJ also was identified as a predictor of sprint ability which is in line with our study. Strong correlations of $r=-0.72$ to $r=-0.73$ were revealed between SJ average power, SJ peak power and $10 \mathrm{~m}$ sprint time in the study of Maulder et al. [24]. This indicates the importance of power production from the leg musculature in sprint performance.

Especially, we found that jump height and contact time were correlated moderately with $20 \mathrm{~m}$ sprint time in Squat Jump (SJ). These findings are in contrast with Maulder and Cronin [25] who found a strong relationship between $20 \mathrm{~m}$ sprint performance and horizontal jumps in male sprinters. In addition, we revealed a negative correlation between SJ power and $10 \times 5 \mathrm{~m}$ sprint time. Findings of this study emphasise the important association between concentric power and sprint performance. In a Squat Jump, the jumper starts from a stationary semi-squatted position then vigorously extends the knees and hips to jump vertically up off the ground [15]. This suggests that an athlete's relative explosive ability of the hip and knee extensors is critical for sprint performance. In fact, the elastic energy has been suggested to be necessary for sprint performance [26]. Taken together these relationships suggest a possible transfer from the gain in leg muscle power during squat jump into enhanced sprint performance. Indeed, a number of studies have previously reported that Futsal players have a significantly lower sprint running performance (10-15 $\mathrm{m}$ ) and knee extension strength or power than soccer players. This could be probably related to a number of factors including lower globalization and international player recruitment, lower financial and social incentives, and fewer advances in nutrition, ergogenic aids, training methods or medical and kinesiological development techniques due to lower financial and social incentives [13]. Although making comparisons with research in other sports has its limitations due to differences in rules, play field, and duration, Futsal is a multiple sprint sport in which highintensity exercise constitutes a greater proportion of match time than in football and other multiple-sprint sports.

\subsubsection{Multiple Regression Equations of Vertical Jumping and Sprinting Measures}

The multiple regressions showed that $\left(\mathrm{VO}_{2}\right.$ max $)$, jump height, power and contact time during squat jump were the determinants of sprinting performances in elite Futsal Tunisian players.

In summary, the relationships observed in our study between sprint performance measures, vertical jumping 
and aerobic fitness in elite Futsal Tunisian players suggest that those with higher aerobic fitness $\left(\mathrm{VO}_{2} \max \right)$ and anaerobic power (vertical jump height, contact time and power during squat jump) tend to have a higher sprint performance. Therefore, muscle power and maximum oxygen uptake seem to be important physiological characteristics for sprinting performance in Tunisian Futsal players.

\section{Practical Applications}

The present study may be used as a base of comparison for further studies and help coaches to analyze the physical and physiological profiles of their teams. The data presented in this article will help practitioners and coaches to better design training by emphasizing the importance of combining adapted leg muscular power training with sprint running training programs for improving short-distance sprint performance. Elite Futsal players require a well developed aerobic fitness and repeated sprint ability to play successfully.

\section{Acknowledgments}

This study was supported by the Tunisian Ministry of Higher Education and Scientific Research.

There is no conflict of interest regarding the information provided in this study.

Special thanks to Professor Fethi Chehata for English correction.

\section{References}

[1] Álvarez, J., Gimenez, L., Corona, P., \& Manonelles, P. (2002). Necesidades cardiovasculares y metabólicas del fútbol-sala: análisis de la competición. Apunts. Medicina de l'Esport, 67, 4553.

[2] Barbero Álvarez, JC., D’Ottavio, S., \& Granda-Vera, J. (2009). Aerobic fitness in futsal players of different competitive level. Journal of Strength and Conditioning Research, 23, 2163-2166.

[3] Barbero-Alvarez, JC., Soto, VM., Barbero-Alvarez, V., \& GrandaVera, J. (2008). Match analysis and heart rate of futsal players during competition. Journal of Sports Sciences, 26, 63-73.

[4] Baroni, BM., \& Leal Junior, ECP. (2010). Aerobic capacity of male professional futsal players. Journal of Sports Medicine and Physical Fitness, 50, 395-399.

[5] Berthoin, S., Pelayo, P., Lensel-Corbeil, G., Robin, H., \& Gerbeaux, M. (1996). Comparison of maximal aerobic speed as assessed with laboratory and field measurements in moderately trained subjects. International Journal of Sports Medicine, 17, 525-529.

[6] Bosco, C., Tihanyi, J., \& Viru, A. (1996). Relationships between field fitness test and basal serum testosterone and cortisol levels in soccer players. Clinical Physiology, 16, 317-322.

[7] Bravo, DF., Impellizzeri, FM., Rampinini, E., Castagna, C., Bishop, D., \& Wisloff, U. (2008). Sprint vs. interval training in football. International Journal of Sports Medicine, 29, 668-674.

[8] Buskirk, ER., \& Mendez, J. (1984). Sports science and body composition analysis: emphasis on cell and muscle mass. Medicine \& Science in Sports \& Exercise, 16, 584-593.

[9] Castagna, C., and Barbero-Álvarez, JC. (2010). Physiological demands of an intermittent Futsal-oriented high-intensity test. Journal of Strength and Conditioning Research, 24, 2322-2329.

[10] Castagna, C., D’Ottavio, S., Vera, JG., \& Álvarez, JC. (2009). Match demands of professional Futsal: a case study. Journal of Science and Medicine in Sport, 12, 490-494.
[11] Doğramaci, SN., \& Watsford, ML. (2006). A comparison of two different methods for time-motion analysis in team sports. International Journal of Performance Analysis in Sport, 6, 73-83.

[12] Glatthorn, JF., Gouge, S., Nussbaumer, S., Stauffacher, S., Impellizzeri, FM., \& Maffiuletti, NA. (2011). Validity and reliability of optojump photoelectric cells for estimating vertical jump height. Journal of Strength and Conditioning Research, 25, 556-560.

[13] Gorostiaga, EM., Llodio, I., Ibáñez, J., Granados, C., Navarro, I., Ruesta, M., Bonnabau, H., \& Izquierdo, M. (2009). Differences in physical fitness among indoor and outdoor elite male soccer players. European Journal of Applied Physiology, 106, 483-491.

[14] Impellizzeri, FM., Marcora, SM., Castagna, C., Reilly, T., Sassi, A., Iaia, FM., \& Rampinini, E. (2006). Physiological and performance effects of generic versus specific aerobic training in soccer players. International Journal of Sports Medicine, 27, 483492.

[15] Komi, PV., \& Bosco, C. (1978). Utilization of stored elastic energy in leg extensor muscles by men and women. Medicine \& Science in Sports, 10, 261-265.

[16] Lacour, JR., Padilla-Magunacelaya, S., Chatard, JC., Arsac, L., \& Barthelemy, JC. (1991). Assessment of running velocity at maximal oxygen uptake. European Journal of Applied Physiology, 62, 77-82.

[17] Leal Junior, EC., Souza, FB., Magini, M., \& Lopes Martins, RAB. (2006). Comparative study of the oxygen consumption and anaerobic threshold in a progressive exertion test in professional soccer and indoor soccer players. Revista Brasileira de Medicina do Esporte, 12, 323-326.

[18] Leger, A., \& Boucher, R. (1980). An indirect continuous running multistage field test: the University de Montreal Track Test. Canadian journal of sport sciences, 5, 77-84.

[19] Leger, A., \& Lambert, J. (1982). A maximal multistage 20-m shuttle run test to predict $\mathrm{VO}_{2}$ max. European Journal of Applied Physiology, 49, 1-12.

[20] Léger, A., Lambert, J., Goulet, A., Rowan, C., \& Dinelle, Y. (1984). Capacité aérobie des Québécois de 6 à 17 ans. Test navette de vingt mètres avec palliers d'une minute. Canadian journal of sport sciences, 14, 21-26.

[21] Lima, AMJ., Silva, DVG., \& Souza, AOS. (2005). Correlation between direct and indirect $\mathrm{VO}_{2 \text { max }}$ measurements in indoor soccer players. Revista Brasileira de Medicina do Esporte, 11, 164-166.

[22] Makaruk, H., Makaruk, B., \& Kędra, S. (2008). Effects of warmup stretching exercises on sprint performance. Physical Education and Sport, 52, 23-26.

[23] Markovic, G., Dizdar, D., Jukic, I., \& Cardinale, M. (2004). Reliability and factorial validity of squat and countermovement jump tests. Journal of Strength and Conditioning Research, 18, 551-555.

[24] Maulder, PS., Bradshaw, EJ., \& Keogh, J. (2006). Jump Kinetic determinants of sprint acceleration performance from starting blocks in male sprinters. Journal of Sports Science \& Medicine, 5, 359-366.

[25] Maulder, P., \& Cronin, J. (2005). Horizontal and vertical jump assessment: reliability, symmetry, discriminative and predictive ability. Physical Therapy in Sport, 6, 74-82.

[26] Mero, A., Komi, PV., \& Gregor, RJ. (1992). Biomechanics of sprint running. Journal of Sports Medicine, 13, 376-392.

[27] Rampinini, E., Bishop, D., Marcora, SM., Ferrari Bravo, D., Sassi, R., \& Impellizzeri, FM. (2007). Validity of simple field tests as indicators of match-related physical performance in top-level professional soccer players. International Journal of Sports Medicine, 28, 228-235.

[28] Rienzi, E., Drust, B., Reilly, T., Carter, JE., \& Martin, A. (2000). Investigation of anthropometric and work-rate profiles of elite South American international soccer players. Journal of Sports Medicine and Physical Fitness, 40, 162-169.

[29] Stølen, T., Chamari, K., Castagna, C., \& Wisløff, U. (2005). Physiology of soccer: An update. Sports Medicine, 35, 501-536.

[30] Wisløff, U., Castagna, C., Helgerud, J., Jones, R., \& Hoff, J. (2004). Strong correlation of maximal squat strength with sprint performance and vertical jump height in elite soccer players. British Journal of Sports Medicine, 38, 285-288. 